\title{
The Influence of Leukocyte and Platelet Concentrate Enrich in Stem Cells on Bone Regeneration Processes: A Clinical and Flow Cytometry Study
}

\author{
Tomasz Bielecki1 ${ }^{*}$, Krzysztof Wójcik1, Tadeusz Bold1', Bartłomiej Osadnik¹, \\ Tomasz Szczepański² \\ ${ }^{1}$ Department and Clinic of Orthopaedics, Trauma Center St. Barbara Hospital, Medical University of Silesia, \\ Sosnowiec, Poland \\ ${ }^{2}$ Department and Clinic of Hematology and Pediatric Oncology, Medical University of Silesia, Zabrze, Poland \\ Email: tomekbiel@tlen.pl
}

Received 21 October 2014; accepted 21 September 2015; published 24 September 2015

Copyright (C) 2015 by authors and Scientific Research Publishing Inc.

This work is licensed under the Creative Commons Attribution International License (CC BY).

http://creativecommons.org/licenses/by/4.0/

(c) (i) Open Access

\section{Abstract}

This article reports the efficacy of percutaneous autologous leukocyte- and platelet-rich plasma (L-PRP) injection into delayed union site as a minimally invasive method alternative to bone marrow aspirate and open grafting techniques. Each of 15 participants was followed on a regular basis with clinical examinations, roentgenograms. The average time to union was 8.4 weeks after L-PRP injection and the union was achieved in all cases. CD34+/45+ cells counts were increased by $410 \%$ and CD34+/45- cells counts were increased by $488 \%$ on average in L-PRP. Our investigation showed that L-PRP enrich in stem cells can produce the desired stimulatory response despite a substantial amount of vital bone cells from mesenchymal line. We believe that the using of L-PRP enriched in stem cells, growth factors and antimicrobial proteins might be a promising treatment method in regenerative medicine.

\section{Keywords}

Healing, Growth Factors, Induction, Stimulation, Osteogenesis

\footnotetext{
${ }^{*}$ Corresponding author.
}

How to cite this paper: Bielecki, T., Wójcik, K., Bold, T., Osadnik, B. and Szczepański, T. (2015) The Influence of Leukocyte and Platelet Concentrate Enrich in Stem Cells on Bone Regeneration Processes: A Clinical and Flow Cytometry Study. J. Biomedical Science and Engineering, 8, 659-664. http://dx.doi.org/10.4236/jbise.2015.89062 


\section{Introduction}

Due to their numerous key properties, platelets started to be used in the contemporary medicine in the strategies of stimulation of tissue healing, as an autologous cell and plasma fraction extracted from the peripheral blood [1]. The autologous whole blood undergoes centrifugation in order to obtain a concentrate of platelets-called platelet-rich plasma (PRP) like in transfusion medicine-which could be transformed into a fibrin gel after activation by the addition of thrombin and calcium ions (or equivalent technologies). Most authors believe that the gel activation and the release of the growth factors lead to the acceleration of the wound healing process [2]. The impact of platelet growth factors was particularly intensively investigated and debated in trauma and maxillofacial applications [3]-[13], and PRP/PRF technology for regenerative medicine treatments is one of the most active fields of research in the dental/maxillofacial and orthopedic literature, with implant surfaces/designs and bone bioengineering [14]-[20].

Since the early development of these technologies, researchers were mostly focused on the platelet count in the concentrates. However, PRPs can contain a significant number of leukocytes and other unknown cells. In the present study, we report the influence of L-PRP on regeneration of tibial fractures. To our knowledge, this is the first report of concentrated stem cells in L-PRP harvested from blood.

\section{Material and Methods}

The study group consisted of 15 patients treated at our clinic with delayed union after tibial open fracture (II stage in Gustilo-Anderson scale) and blocked intramedullary nail fixation. Basic characteristics of the study population are summarised in Table 1.

For the study, $108 \mathrm{ml}$ of whole blood was collected from each subject into a syringe containing $12 \mathrm{ml}$ of citrate solution. Whole blood was drawn into two sterile tubes and centrifuged for 15 minutes at 3200 RPM (GPS II Platelet Concentration System, Biomet, Warsaw, USA). This resulted in blood separation into its three basic components: red blood cells, L-PRP sometimes referred to as "buffy coat", and acellular plasma (ACP). Subsequently, ACP component was removed into $60 \mathrm{ml}$ syringe. Next the tube was shacked vigorously for 30 seconds to suspend platelets and $12 \mathrm{ml}$ of L-PRP was obtained.

\subsection{Surgical Procedure}

Before investigation informed consent was obtained from the patients. The surgical procedure was performed in the operating room under general anesthesia. An 18-gauge or biopsy needle was introduced immediately into the gap of nonunion under fluoroscopic guidance. In all cases, L-PRP and $3 \mathrm{ml}$ of autologous thrombin solution (TPD, Biomet, Warsaw, USA), a total of $15 \mathrm{ml}$, was injected by dual syringe applicator system (Biomet Inc.) into the disturbed bone-healing area forming a gelatinous mass. A second injection into the gap or operation with bone grafts was not performed.

\subsection{Cell Preparation, Flow-Cytometric Analysis, and Cell Sorting}

Blood and L-PRP samples were processed under standardized and optimized conditions within less than 5 hours after collection. For each sample two 8-fold staining with fluorochrome-conjugated mouse anti-human monoclonal antibodies were performed.

The antibody set was designed to allow leukocyte analysis, so the antibodies against lineage specific progenitor stem cells surface markers were used: hematopoietic line (CD34+/CD45+) and peripheral blood-derived endothelial progenitor cells (CD34+/CD45-).

After staining step, erythrocyte lysis and fixation was performed with FACSLyse Solution (Becton Dickinson). Subsequently the sample was washed with Cell Wash solution (Becton Dickinson) and finally resuspended in FACSFlow solution (Becton Dickinson).

Table 1. Characteristics of the study population.

\begin{tabular}{ccc}
\hline Variable & Mean + SD or n (\%) \\
\hline Age (years) & $36 \pm 7$ \\
Female/male & $8(53 \%) / 7(47 \%)$ \\
\hline
\end{tabular}


Acquisition of data was performed in 8-color 3-laser flow cytometer FACSCanto II (Becton Dickinson Immunocytometry Systems, San Jose, CA, USA). The data were acquired and analyzed with Diva software (Becton Dickinson).

The Silesian Medical University Ethics Committee approval for performing investigation was obtained.

\section{Results}

No complications related to surgical technique were observed. Several patients, particularly with fibular and tibial healing disturbances, developed subcutaneous swelling of few centimeters in diameter at the injection site. These areas were first evident during injection and resolved within several hours. A few patients had moderate discomfort at their donor vein site, which generally resolved within a few hours. The average hospital stay per patient was 1.9 days. No infection complicating bone healing was observed. Union was observed in all cases. The average time to union was 8.4 weeks (range 5 - 12 weeks) after L-PRP injection.

We found markedly increased platelet and leukocyte counts (more than sevenfold) compared with baseline levels. Adult stem cell counts were also increased. Figure 1 shows the results of the adult stem cell from hematopoietic line measurements for the blood and L-PRP. Peripheral blood-derived endothelial progenitor cells were also detected in blood and L-PRP samples.

\section{Discussion}

Most authors use platelet separation systems, which allow to collect leukocytes [21]-[24]. However, some authors exclude leukocytes from L-PRP, so they obtain pure PRP [14] [25]. In Aspenberg and Virchenko studies L-PRP was irradiated at 25 Gy to inactivate the WBCs, and truly platelet concentrate was reached [25]. For non-advanced reader the distinction between two similar, but not the same biomaterials could be unfulfillable. The truth is that many authors do not mention about leukocytes concentration even though they use standard separator system and focus only at platelets and growth factors [26]. That is why Everts et al. and Bielecki et al. proposed term "platelet-leukocyte-rich plasma or gel (PLRP/PLRG)", independently [23] [27], and in 2012 Dohan Ehrenfest study team consisting from blood concentrate specialists reached consensus in terminology and leukocyte- and platelet-rich plasma/fibrin "L-PRP/L-PRF” term is finally used. [1].

The usage of L-PRP to enhance bone regeneration and soft tissue maturation has also increased in the field of

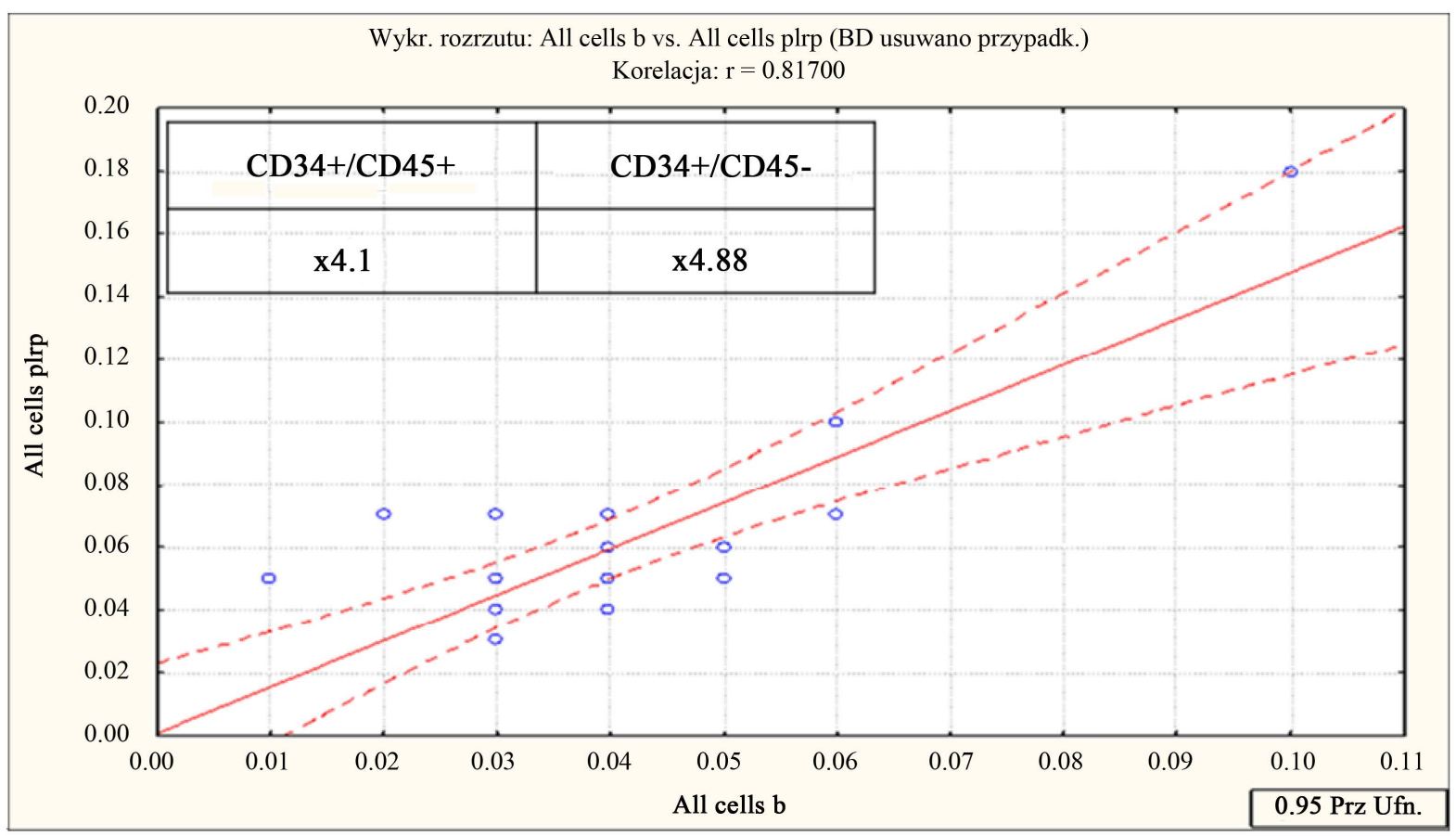

Figure 1. CD34+/45+ cells counts were increased by $410 \%$ and CD $34+/ 45-$ cells counts were increased by $488 \%$ on average. 
orthopaedic and trauma surgery over the last decade [27]. Lowery et al. [28] used PLRG with allogenic grafts in lumbar spinal fusion with good results. They did not observe any radiological or clinical evidence of pseudoarthrosis in all patients. Bielecki and Gazdzik [10] showed a case report of L-PRP treatment in a patient who suffered from disturbances of bone-healing processes. Kitoh et al. [29] reviewed clinical results of distraction osteogenesis with transplantation of marrow-derived mesenchymal stem cells and PLRG in 3 patients. A mixture of PLRG and osteoblast-like cells were injected into the callus. In 1 case they had to increase the distraction to $1.5 \mathrm{~mm} /$ day between days 34 and 47, because callus formation was likely to consolidate prematurely. Enhanced callus formation was observed radiographically after first transplantation of marrow-derived mesenchymal stem cells and PLRG in all 3 cases. However, they applied a combination of two osteoinductive biomaterials and we do not know to what extent PLRG influenced bone formation in these cases [29].

Our investigation showed that percutaneous L-PRP injection is a sufficient method to treat delayed union and is less invasive procedure than bone marrow injection. Additional advantages include decreased hospitalization costs and duration. Although autologous bone marrow collection is thought to be a relatively simple procedure, it can be associated with numerous complications such as biopsy site bleeding, hematoma and/or infection [7] [27]. The application of L-PRP under fluoroscopic guidance lasts about 1 - 2 min and can be performed under short-term intravenous general anesthesia. L-PRP injection into the healing disturbances site is a minimal invasive surgical procedure and can be easily done in the outpatient clinic.

Until now, no one has published the adult stem cells in L-PRP in patients with bone healing disturbances. We know that leukocytes and their progenitors are cells of the immune system defending the body against both infectious disease and foreign materials. Particularly T-lymphocytes, might mediate rejection and destruction of allogenic grafts, which are widely used in orthopaedic surgery [30]. Taking into account significant numbers of progenitors in L-PRP, immunogenic allograft might retard healing processes or even induce local immune response causing bone destruction [30].

Most progenitors (adult stem cells) are described as multipotent [31]. They are in the "center" between stem cells and fully differentiated cell. Like stem cells, mostly, they are formed and transported in a colony, with the right conditions for them to grow and differentiate into their target tissues [31] [32]. Our study showed that after blood separation process the higher level of CD34+ cells is reached. It opens a new direction of investigations. It is possible that platelet-derived growth factors can induced progenitor cells from L-PRP in first stage to excrete numerous growth factors, which can stimulate bone healing by autocrine, paracrine and juxtacrine interactions. In consequence, osteogenic cells from bone matrix are activated and regeneration processes can occur. However, further studies are necessary to fully elucidate the role of stem cells from L-PRP.

\section{Acknowledgements}

This work was supported by the Committee for Scientific Research, Medical University od Silesia, Poland, No. 4120/P01/2013.

\section{References}

[1] Dohan Ehrenfest, D.M., Bielecki, T., Mishra, A., Borzini, P., Inchingolo, F., Sammartino, G., Rasmusson, L. and Evert, P.A. (2012) In Search of a Consensus Terminology in the Field of Platelet Concentrates for Surgical Use: Platelet-Rich Plasma (PRP), Platelet-Rich Fibrin (PRF), Fibrin Gel Polymerization and Leukocytes. Current Pharmaceutical Biotechnology, 13, 1131-1137. http://dx.doi.org/10.2174/138920112800624328

[2] Bielecki, T. and Dohan Ehrenfest, D.M. (2012) Platelet-Rich Plasma (PRP) and Platelet-Rich Fibrin (PRF): Surgical Adjuvants, Preparations for in Situ Regenerative Medicine and Tools for Tissue Engineering. Current Pharmaceutical Biotechnology, 13, 1121-1130. http://dx.doi.org/10.2174/138920112800624292

[3] Cieslik-Bielecka, A., Choukroun, J., Odin, G. and Dohan Ehrenfest, D.M. (2012) L-PRP/L-PRF in Esthetic Plastic Surgery, Regenerative Medicine of the Skin and Chronic Wounds. Current Pharmaceutical Biotechnology, 13, 12661277. http://dx.doi.org/10.2174/138920112800624463

[4] Clark, R.A. (2001) Fibrin and Wound Healing. Annals of the New York Academy of Sciences, 936, 355-367. http://dx.doi.org/10.1111/j.1749-6632.2001.tb03522.x

[5] Gibble, J.W. and Ness, P.M. (1990) Fibrin Glue: The Perfect Operative Sealant? Transfusion, 30, 741-747. http://dx.doi.org/10.1046/j.1537-2995.1990.30891020337.x

[6] Del Corso, M., Vervelle, A., Simonpieri, A., et al. (2012) Current Knowledge and Perspectives for the Use of PlateletRich Plasma (PRP) and Platelet-Rich Fibrin (PRF) in Oral and Maxillofacial Surgery Part 1: Periodontal and Dentoal- 
veolar Surgery. Current Pharmaceutical Biotechnology, 13, 1207-1230.

http://dx.doi.org/10.2174/138920112800624391

[7] Bielecki, T.M. and Gaździk, T.S. (2006) Percutaneous Injection of Autogenous Growth Factors in Patient with Nonunion of the Humerus. A Case Report. Journal of Orthopaedics, 3, e15.

[8] Mishara, A. and Pavelko, T. (2006) Treatment of Chronic Elbow Tendinosis with Buffered Platelet-Rich Plasma. The American Journal of Sports Medicine, 34, 1774-1778. http://dx.doi.org/10.1177/0363546506288850

[9] Marx, R.E., Carlson, E.R., Eichstaedt, R.M., Schimmele, S.R., Strauss, J.E. and Georgeff, K.R. (1998) Platelet-Rich Plasma: Growth Factor Enhancement for Bone Grafts. Oral Surgery, Oral Medicine, Oral Pathology, Oral Radiology, and Endodontology, 85, 638-646. http://dx.doi.org/10.1016/S1079-2104(98)90029-4

[10] Bielecki, T.M. and Gaździk, T.S. (2007) Percutaneous Injection of Autologous Platelet-Rich Gel in a Patient with an Infected Nonunion of the Tibia. A Case Report and Review of the Literature. Journal of Orthopaedics Trauma Surgery and Related Research, 2, s69-s72.

[11] Moojen, D.J., Everts, P.A., Schure, R.M., Overdevest, E.P., van Zundert, A., et al. (2008) Antimicrobial Activity of Platelet-Leukocyte Gel against Staphylococcus Aureus. Journal of Orthopaedic Research, 26, 404-410. http://dx.doi.org/10.1002/jor.20519

[12] Weibrich, G., Hansen, T., Kleis, W., Buch, R. and Hitzler, W.E. (2004) Effect of Platelet Concentration in PlateletRich Plasma on Peri-Implant Bone Regeneration. Bone, 34, 665-671. http://dx.doi.org/10.1016/j.bone.2003.12.010

[13] Mishra, A., Harmon, K., Woodall, J. and Vieira, A. (2012) Sports Medicine Applications of Platelet Rich Plasma. Current Pharmaceutical Biotechnology, 13, 1185-1195. http://dx.doi.org/10.2174/138920112800624283

[14] Anitua, E., Sanchez, M., Orive, G. and Andia, I. (2007) The Potential Impact of the Preparation Rich in Growth Factors (PRGF) in Different Medical Fields. Biomaterials, 28, 4551-4560. http://dx.doi.org/10.1016/j.biomaterials.2007.06.037

[15] Toeroek, R. and Dohan Ehrenfest, D.M. (2013) The Concept of Screw-Guided Bone Regeneration (S-GBR). Part 2: SGBR in the Severely Resorbed Preimplant Posterior Mandible Using Bone Xenograft and Leukocyte- and PlateletRich Fibrin (L-PRF): A 5-Year Follow-Up. POSEIDO, 1, 85-92.

[16] Cieslik-Bielecka, A., Choukroun, J., Odin, G. and Dohan Ehrenfest, D.M. (2012) L-PRP/L-PRF in Esthetic Plastic Surgery, Regenerative Medicine of the Skin and Chronic Wounds. Current Pharmaceutical Biotechnology, 13, 12661277. http://dx.doi.org/10.2174/138920112800624463

[17] Everts, P.A., Hoffmann, J., Weibrich, G., Mahoney, C.B., Schönberger, J.P.A.M., et al. (2006) Differences in Platelet Growth Factor Release and Leucocyte Kinetics during Autologous Platelet Gel Formation. Transfusion Medicine, 16, 363-368. http://dx.doi.org/10.1111/j.1365-3148.2006.00708.x

[18] Everts, P.A., van Zundert, A., Schonberger, J.P., Devilee, R.J. and Knape, J.T. (2008) What Do We Use: Platelet-Rich Plasma or Platelet-Leukocyte Gel? Journal of Biomedical Materials Research Part A, 85, 1135-1136. http://dx.doi.org/10.1002/jbm.a.31570

[19] Cieślik, T., Skowronek, J., Cieślik, M. and Cieślik-Bielecka, A. (2009) Bone Graft Application from Anterior Sinus Maxillary Wall in Orbital Floor Reconstruction. Journal of Craniofacial Surgery, 20, 512-515. http://dx.doi.org/10.1097/SCS.0b013e31818436a5

[20] Malhotra, A., Pelletier, M.H., Yu, Y. and Walsh, W.R. (2013) Can Platelet-Rich Plasma (PRP) Improve Bone Healing? A Comparison between the Theory and Experimental Outcomes. Archives of Orthopaedic and Trauma Surgery, 133, 153-165. http://dx.doi.org/10.1007/s00402-012-1641-1

[21] Frechette, J.P., Martineau, I. and Gagnon, G. (2005) Platelet Rich Plasmas: Growth Factor Content and Roles in Wound Healing. Journal of Dental Research, 84, 434-439. http://dx.doi.org/10.1177/154405910508400507

[22] Yuan, T., Zhang, C. and Zeng, B. (2008) Treatment of Chronic Femoral Osteomyelitis with Platelet-Rich Plasma (PRP): A Case Report. Transfusion and Apheresis Science, 38, 167-173. http://dx.doi.org/10.1016/j.transci.2008.01.006

[23] Everts, P.A., Devilee, R.J., Brown Mahoney, C., van Erp, A., Oosterbos, C.J., Stellenboom, M., Knape, J.T. and van Zundert, A. (2008) Exogenous Application of Platelet-Leukocyte Gel during Open Subacromial Decompression Contributes to Improved Patient Outcome. A Prospective Randomized Double-Blind Study. European Surgical Research, 40, 203-210. http://dx.doi.org/10.1159/000110862

[24] Khalafi, R.S., Bradford, D.W. and Wilson, M.G. (2008) Topical Application of Autologous Blood Products during Surgical Closure Following a Coronary Artery Bypass Graft. European Journal Cardio-Thoracic Surgery, 34, 360-364. http://dx.doi.org/10.1016/j.ejcts.2008.04.026

[25] Aspenberg, P. and Virchenko, O. (2004) Platelet Concentrate Injection Improves Achilles Tendon Repair in Rats. Acta Orthopaedica Scandinavica, 75, 93-99. http://dx.doi.org/10.1080/00016470410001708190 
[26] Bielecki, T., Gazdzik, T.S. and Szczepanski, T. (2006) What Do We Use: Platelet-Rich Plasma or Platelet-Rich Gel? Bone, 39, 1388,. http://dx.doi.org/10.1016/j.bone.2006.06.015

[27] Bielecki, T., Gazdzik, T.S and Szczepanski, T. (2008) Benefit of Percutaneous Injection of Autologous Platelet-Leukocyte-Rich Gel in Patients with Delayed Union and Nonunion. European Surgical Research, 40, 289-296. http://dx.doi.org/10.1159/000114967

[28] Lowery, G.L., Kulkarni, S. and Pennisi, A.E. (1999) Use of Autologous Growth Factors in Lumbar Spinal Fusion. Bone, 25, 47S-50S. http://dx.doi.org/10.1016/S8756-3282(99)00132-5

[29] Kitoh, H., Kitakoji, T., Tsuchiya, H., Katoh, M. and Ishiguro, N. (2007) Transplantation of Culture Expanded Bone Marrow Cells and Platelet Rich Plasma in Distraction Osteogenesis of the Long Bones. Bone, 40, 522-528. http://dx.doi.org/10.1016/j.bone.2006.09.019

[30] Bielecki, T., Cieslik-Bielecka, A., Zelawski, M. and Mikusek, W. (2012) A Side-Effect Induced by the Combination of a Demineralized Freeze-Dried Bone Allograft and Leucocyte and Platelet-Rich Plasma during Treatment for Large Bone Cysts: A 4-Year Follow-Up Clinical Study. Transfusion and Apheresis Science, 47, 133-138. http://dx.doi.org/10.1016/j.transci.2012.06.017

[31] Seaberg, R.M. and van der Kooy, D. (2003) Stem and Progenitor Cells: The Premature Desertion of Rigorous Definitions. Trends in Neurosciences, 26, 125-131. http://dx.doi.org/10.1016/S0166-2236(03)00031-6

[32] Ciurea, M.E., Georgescu, A.M., Purcaru, S.O., Artene, S.A., Emami, G.H., Boldeanu, M.V., Tache, D.E. and Dricu, A. (2014) Cancer Stem Cells: Biological Functions and Therapeutically Targeting. International Journal of Molecular, 15, 8169-8185. http://dx.doi.org/10.3390/ijms15058169 